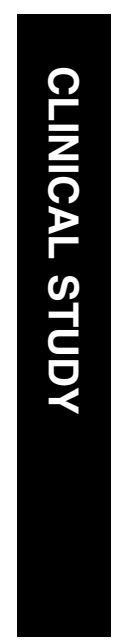

\title{
Regression of early diabetic macular oedema is associated with prevention of dark adaptation
} ${ }^{1}$ School of Community and
Health Sciences, City University, London, UK

${ }^{2}$ King's College Hospital NHS Foundation Trust, London, UK

${ }^{3}$ Moorfields Eye Hospital NHS Foundation Trust London, UK

Correspondence: GB Arden, School of Community and Health Sciences, City University, Northampton Square, London EC1V OHB, UK.

Tel: +44 (0)207359 9080;

Fax: + 44 (0)207 0406635

E-mail: geoffreyarden@

aol.com

Received: 8 July 2011 Accepted in revised form: 2 August 2011

Published online:

21 October 2011

\begin{abstract}
Hypothesis Dark-adapted rods consume oxygen at high rates and light adaptation decreases this oxygen burden and can have therapeutic effects on diabetic macular oedema (DMO).

Methods Patients with mild nonproliferative diabetic retinopathy (DR) and early, untreated non-sight-threatening DMO slept for $\mathbf{6}$ months wearing masks that illuminated the eyelid of one closed eye by $505 \mathrm{~nm}$ light. Exclusion criteria were any concomitant eye disease, DR $>$ ETDRS grade 35 , and other systemic diseases. Primary outcome: change of OCT retinal thickness in the local region where oedema was present. Results A total of 34 out of 40 patients completed the study. Mean baseline OCT macular cube thickness was equivalent for study and fellow eyes. But study eyes had a greater mean thickness in the central subfield zone $1(282 \pm 53 \mu \mathrm{m})$ vs $(256 \pm 19 \mu \mathrm{m})$ the fellow eyes. Twenty-eight study eyes showed intraretinal cysts compared with nine in the fellow eyes. At 6 months, only 19 study eyes had cysts while cysts were seen in 20 fellow eyes. After 6 months, the worst affected ETDRS zone and the central subfield zone 1 reduced in thickness in study eyes only by $12 \mu \mathrm{m}(95 \%$ CI 20 to $-7, P=0.01)$. The secondary outcomes of change in visual acuity, achromatic contrast sensitivity, and microperimetric thresholds improved significantly in study eyes and deteriorated in fellow eyes.

Conclusions Sleeping in dim light that can keep rods light adapted may reverse the changes of DMO.

Eye (2011) 25, 1546-1554; doi:10.1038/eye.2011.264; published online 21 October 2011
\end{abstract}

GB Arden', S Jyothi², CH Hogg ${ }^{3}$, YF Lee² and S Sivaprasad ${ }^{2}$

Keywords: lightmasks; diabetic macular oedema; hypoxia; dark; adaptation

Introduction

Recent clinical trials have shown that intravitreal injections of inhibitors of vascular endothelial growth factor (VEGF) can improve visual function and retinal morphology in patients with diabetic retinopathy (DR), and diabetic macular oedema (DMO). ${ }^{1-4}$ In such patients, there may be widespread loss of retinal capillaries that lead to retinal hypoxia, which is known as the most potent stimulus for VEGF upregulation. VEGF has properties that could cause the vascular damage observed in DR and DMO. ${ }^{5}$ But in cat and man there is evidence of hypoxia before any capillary dropout. In the $\mathrm{cat}^{6,7}$ the evidence is from direct measurement of intraretinal $\mathrm{pO}_{2}$ using oxygen microelectrodes. In man, before any vasculopathy can be demonstrated, dark adaptation is incomplete, ${ }^{8}$ colour discrimination sensitivity ${ }^{9}$ and achromatic contrast sensitivity decline, ${ }^{10}$ and decrease of the oscillatory potentials can be seen. ${ }^{11}$ These early changes are likely to be associated with hypoxia because they are partially, rapidly, and transiently reversed by oxygen inhalation. The cause of these changes remains unclear. It is to this problem that the present work is directed. One fundamental observation is that the vascular changes seen in retinal vessels do not occur in brain tissue although the tissues have similar origins. There must therefore be a specific retinal peculiarity causing DR. ${ }^{12}$ The main difference between the brain and retina - that is the presence of photoreceptors - may be responsible for the retinal susceptibility. There is 
considerable evidence to support this view. ${ }^{13-18}$ These and other observations have led to a different proposal about the pathophysiology of DR. ${ }^{19,20-22}$ The oxygen demand of rods, in the outer retina, is much increased in darkness ${ }^{6,7,13,23-25}$ and this in turn causes a reduction in inner retinal oxygen tension. ${ }^{11,25}$ It has been suggested that the increasing inner retinal hypoxia in diabetes causes the upregulation of cytokines, most importantly VEGF, to a degree that produces damage to small retinal vessels, thus reducing local capillary blood flow and increasing hypoxia in a vicious circle. This hypothesis predicts that prevention of dark adaptation should reduce the rate of progression of $\mathrm{DMO}^{22-24}$ because outer retinal hypoxia increases considerably in dark adaptation. $^{6}$

A phase I clinical trial involving 12 patients with mild non-proliferative DR showed that trans-eyelid illumination of the retina during sleep was acceptable by patients, had no reported ill effects, and also improved DR and visual function. ${ }^{26}$ In the light of this finding, we have conducted a further investigation on patients with early DMO. We hypothesised that DMO would be as susceptible to this intervention as had DR.

\section{Materials and methods}

This study was conducted in accordance with the Declaration of Helsinki, and approval was obtained from King's College Hospital Ethics Committee (ISRCTN34037927; R\&D 08/H0808/198). Written informed consent was obtained from all participants.

Subjects were recruited from the Medical Retina clinics of King's College Hospital NHS Foundation Trust. The inclusion criteria were: (1) clinical evidence of focal macular thickening that was clinically nonsignificant within two disc diameters of the centre of the fovea or too close to the foveal avascular zone for laser treatment; (2) an Early Treatment Diabetic Retinopathy Study (ETDRS) retinopathy severity level between 20 and 35; (3) a BCVA of 60 or more letters (ETDRS $4 \mathrm{~m}$ protocol); (4) no history of scatter (panretinal) or focal/grid photocoagulation for DR; and (5) no evidence of other ocular pathology that could interfere with ocular examination and visual acuity assessment during the 6-month study period. The exclusion criteria were: (1) clinically significant macular oedema with visual acuity of $<70$ letters that was amenable to laser photocoagulation at baseline according to ETDRS guidelines; (2) visual acuity reduction that could not be attributable to DR; and (3) any other concomitant ocular or systemic conditions that could influence the natural course of DR.

Patients who, during the study, required additional treatment in the non-study eye due to deterioration in $\mathrm{DMO}$ are not included in the statistical analyses.

\section{Lightmasks-construction and design}

A plastic cup of transparent silicone rubber contained four light-emitting diodes (Nichia NESE021T rank E, Nichia Corporation, Tokushima, Japan). Its concave surface fitted on the closed lid of either a left or right eye. In preliminary experiments (not reported) similar to those described in Arden et $a l^{14}$, we determined that the $505 \mathrm{~nm}$ light used increased rod threshold by $\sim 3 \mathrm{log}$ units before the increment threshold for cones increased. The calculated light intensity at the retina was 2 scotopic Trolands, which would cause a considerable reduction in the rod dark current. ${ }^{24}$ The device was driven by a rechargeable battery (Panasonic UL23300, Panasonic Corporation, Osaka, Japan) connected to a charge-pump chip (Max 1573, Maxim Integrated Products, Inc. Sunnyvale, CA, USA). The battery was recharged each morning. A train of short-light pulses, with variable mark-space ratio, regulated the light output. Each LED drew $\sim 200 \mu$ A current. The printed circuit board was enclosed in a thick cotton cover, held against the eyes by an elastic headband.

\section{Study design}

Eligible patients were provided with the information leaflet, and used the eye mask for a trial period of 1 week before consenting to the study. Following the baseline visit, patients returned at 3 and 6 months for all tests except microperimetry (see below). Patients were contacted in between the visits to reinforce compliance and returned to the study centre if they had any trouble with the masks. Patients were directly questioned about any sleep disturbance but formal sleep questionnaires were not used. The technicians conducting OCT, and psychophysical tests were masked of the study eyes while the physicians and patients were not. Randomisation was not attempted because many patients presented with the diagnosis of unilateral disease.

Best-corrected distance acuity was measured using ETDRS charts (Lighthouse Low Vision Products, New York, NY, USA) at $4 \mathrm{~m}$. The Pelli-Robson contrast sensitivity test was performed using two charts (one for each eye) at a distance of $1 \mathrm{~m}$. Microperimetry was performed with the automated microperimeter (MP1; Nidek Technologies, Padova, Italy) in selected patients who agreed to this examination. The stimulus used was the Goldmann III spot size of 200-ms duration, attenuation $0-20 \mathrm{~dB}$. The foveal and mean retinal sensitivity was recorded. Standard 2-view fundus photographs were taken. Spectral-domain OCT was performed using the Macular Cube $512 \times 128$ scanning protocols (Cirrus, Carl Zeiss Meditec AG, Jena, Germany). Intraretinal cysts were classified as present or 
absent at baseline. As retinal swelling was localised, retinal thickness was also recorded for the nine separate ETDRS zones. Additional treatment (macular laser photocoagulation) was given, if required.

\section{Safety assessments}

All patients were asked if they had any complaints, or discomfort, or any sleep disturbance or mood alterations or changes in wakefulness during the day. These were recorded as adverse events.

\section{Statistical analyses}

Significance for continuous variables was estimated using two-tailed paired $t$-tests. The null hypothesis was rejected for $P<0.05$. The Fisher exact test was also employed.

\section{Study design}

By treating only one eye, we ensured that important variables were equivalent in treated and non-treated eyes (eg, HbA1c, blood pressure, age, sex, smoking, etc). The number of study eyes with intraretinal cysts exceeded those in the fellow eyes, and there was a greater thickness of zone 1 in OCT measurements in study eyes than fellow eyes. For this reason, a

longitudinal analysis of changes in eyes has been carried out for study and fellow eyes independently, in addition to the study-fellow eye comparison.

\section{Outcomes}

This to the best of our knowledge is the first publication in which light masks have been used to treat DMO. It is also the first publication to describe changes in OCT findings with time in patients undergoing treatment for early disease. For this reason, we defined the outcome as a reduction in local retinal swelling, recording the thickness of each of the nine ETDRS regions in the OCT analyses. We here report on zone 1 thickness and the thickness in the most swollen zone, which was always in an intermediate zone (zones 2,3,4, and 5). We also report on the thickness of the zone opposite the zone of maximum thickness, the 'mirror zone'. If the maximum thickness occurred in zone 2, the mirror zone was 4, if 3, 5 and so on. The mirror zone was thus on the same eccentricity as the zone of maximum swelling but as far away from the swelling as possible. The rationale is that it provides an additional control. Reduction of thickness in one zone might occur as a temporary regression, accompanied by concurrent worsening in another: the fact this did (or did not) occur in a zone where swelling was minimal is therefore of interest, as is the change-or absence of change - in untreated eyes examined using the same method of analysis. The psychophysical tests we used were all standard, and results were obtained in exactly the same way as used by previous investigators. We initially measured microperimetric thresholds in the ETDRS zones, but this test was abandoned after 3 months because participants found the test too difficult.

\section{Results}

The study enrolled 5 patients with type I (12\%) and 35 with type II diabetes mellitus. The mean age was 56 years (range 33-75 years). The mean baseline glycated haemoglobin $\left(\mathrm{HbA}_{1 \mathrm{c}}\right)$ was $8.21 \%$ (range $6.0-11.6 \%$ ) and altered at 6 months by $-0.17 \pm 0.88$ (SD). All investigations were carried out between 1400 and 1700 hours.

\section{Dropouts}

Out of the 40 recruited, 6 failed to complete the study; 1 dropped out after 3 months due to inability to keep hospital appointments, and 1 failed to use the lightmask in the first 3 months. Four discontinued because of unrelated ill health. A further four patients were excluded from paired analyses because the unilluminated fellow eyes received laser or intravitreal bevacizumab for progression of DMO during the study. None of the illuminated eyes required such treatment during the study. Thus, a total of 34 patients were included in the analyses of the changes in the illuminated eyes at 6 months. In two cases, 3-month OCT measurements were not done.

\section{Adverse effects}

None of the recruited subjects reported any difficulty in wearing the masks, or any difficulty in sleeping, or mood alteration.

Fundus photographs did not change over 6 months, and are not reported upon further.

\section{OCT results}

At baseline, the mean macular cube thickness was nearly equal for study and fellow eyes $(282 \pm 51 \mu \mathrm{m} v \mathrm{~s}$ $278 \pm 25 \mu \mathrm{m})$, and changed insignificantly during the study $(279 \pm 16 \mu \mathrm{m}$ vs $279 \pm 22 \mu \mathrm{m})$ because the DMO was localised as can be seen in Figure 2.

However, the mean central subfield (zone 1) thickness was higher in the study eyes compared with the fellow eyes. Also, the number of patients in whom an intraretinal cyst was seen in OCT transverse section was greater for study eyes than for fellow eyes (28 in study eyes and 9 in fellow eyes). Representative samples of the morphological regression of intraretinal cysts in the study eyes over the 6 months are given in Figure 1 for 

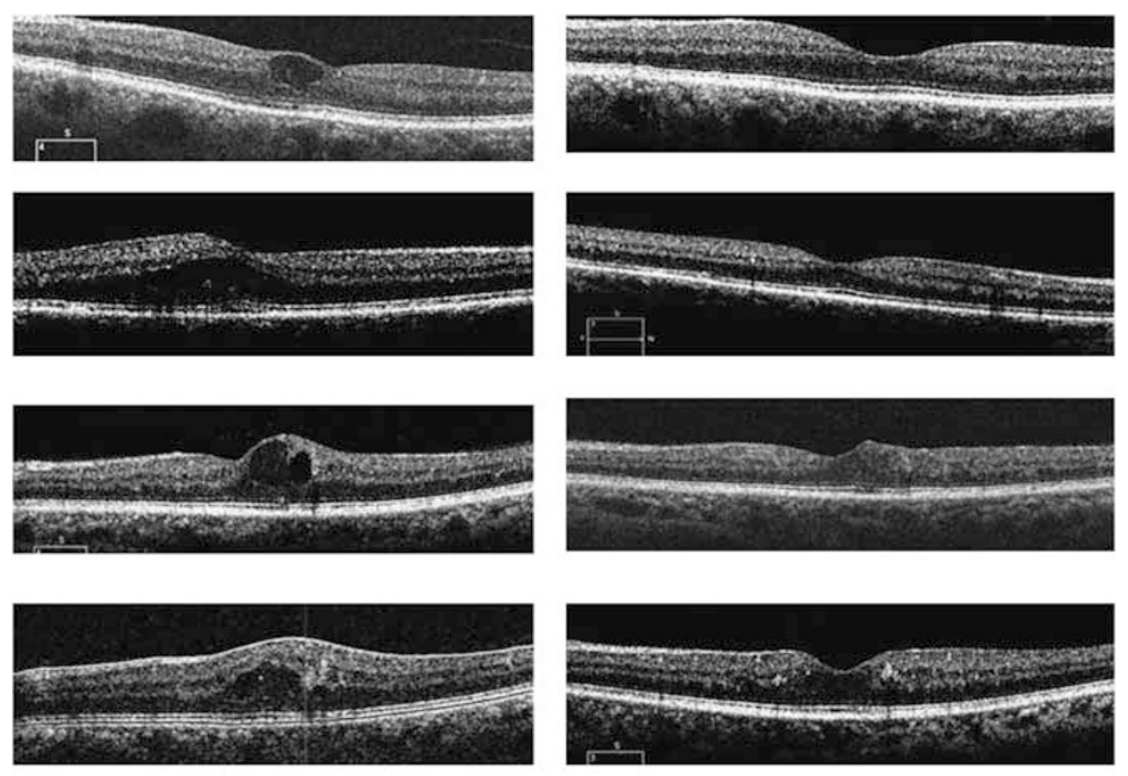

Pre-treatment - trial eyes

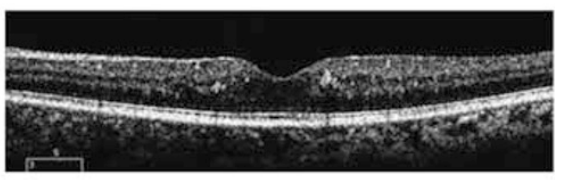

\section{Post-treatment}

Figure 1 Cross-sectional OCT views horizontally through the macula from some representative patients study eyes. In each case, the characteristic cysts have decreased over the course of the study.
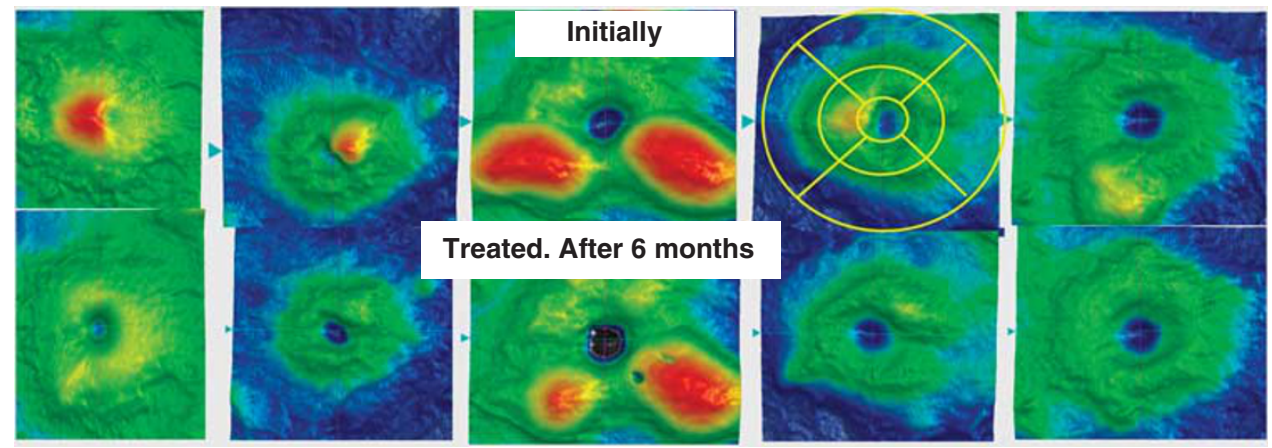

Figure 2 Computed 3-D OCT false colour images in representative patients, showing changes in retinal thickness. Blue and dark green colours are within normal limits, and green, yellow, red, pink, and white represent regions of increased thickness, which varies between patients. Swelling diminishes during the trial. Quantitation of such results was achieved by using the separation of different zones, included in the OCT report, which are indicated for one eye, in the figure. These are based on the ETDRS zones, and results are given in the tables. Zone 1 is the subfoveal zone for the left-handed patient, the zone measured was zone 2, and measurements are also presented from zone 4, opposite it, which is called the 'mirror zone'. For the right-most pair of images, measurements would be taken from zone 5 and its mirror zone, ETDRS zone 3.

cysts and Figure 2 for 3-D false colour views. In the 28 study eyes with an intraretinal cyst at baseline, 9 disappeared or considerably reduced. For fellow eyes, 9 initially showed a cyst but this increased to 20 at the end of the study.

There were also significant changes in the retinal thickness, measured by OCT as shown in Table 1 .

We also calculated the change in the various retinal locations of the study eyes only (Table 2). Only the reduction of thickness in the zone of maximal oedema is significant. The change in thickness of the mirror zones is negligible. Table 2 also gives the changes in dimension for the entire study (months 1-6), and the first half (months 1-3) and second half (months 3-6). There were no significant changes in the fellow eyes (not illustrated).

We also calculated the quantity (change in thickness in study eye)-(change in thickness of its fellow eye) for each of the three zones indicated in Table 1. The difference was significant for central and maximal zones, but not for the mirror zone (Table 3).

Figure 3 shows distribution of the individual differences. For fellow eyes, swelling increases in 16 and 
Table 1 Measurements of retinal thickness in the study and fellow eyes

\begin{tabular}{|c|c|c|c|c|c|c|c|c|c|}
\hline \multirow[t]{3}{*}{ Location } & \multicolumn{4}{|c|}{ Study eyes $\mathrm{n}=34$} & \multicolumn{4}{|c|}{ Fellow eyes $\mathrm{n}=34$} & \multirow{3}{*}{$\begin{array}{l}\text { Change in thickness } \\
\text { (negative = reduction } \\
\text { of thickness) 95\% CI } \\
\text { after } 6 \text { months }\end{array}$} \\
\hline & \multicolumn{2}{|c|}{$\begin{array}{l}\text { Thickness } \\
\text { at baseline } \\
(\mu \mathrm{M})\end{array}$} & \multicolumn{2}{|c|}{$\begin{array}{c}\text { Thickness } \\
\text { after } 6 \text { months } \\
(\mu \mathrm{M})\end{array}$} & \multicolumn{2}{|c|}{$\begin{array}{l}\text { Thickness } \\
\text { at baseline } \\
(\mu \mathrm{M})\end{array}$} & \multicolumn{2}{|c|}{$\begin{array}{c}\text { Thickness } \\
\text { after } 6 \text { months } \\
(\mu M)\end{array}$} & \\
\hline & Mean & $S D$ & Mean & $S D$ & Mean & $S D$ & Mean & $S D$ & \\
\hline Average of cube & 283 & 20 & 282 & 20 & 282 & 23 & 282 & 23 & -13 to +8 \\
\hline ETDRS zone 1 & 277 & 55 & 265 & 55 & 249 & 38 & 248 & 40 & -25 to +0.8 \\
\hline ETDRS zone with maximal thickness & 343 & 48 & 322 & 26 & 333 & 51 & 328 & 39 & -18 to +8 \\
\hline $\begin{array}{l}\text { Opposite (mirror) zone of the maximal } \\
\text { thickness zone in the study eye }\end{array}$ & 318 & 18 & 318 & 20 & 312 & 26 & 310 & 27 & -5.4 to 2.4 \\
\hline
\end{tabular}

Measurements of retinal thickness (outer limiting membrane to retinal pigment epithelium) for the average of the region scanned and three separate zones, corresponding to the ETDRS zones. Note that the average retinal thickness was similar (and within normal limits ${ }^{3}$ ) for trial and fellow eyes. For the central and the most swollen zones, the study eyes improved, but the fellow eyes' corresponding zones did not. For the mirror zones, there was little difference between study and fellow eyes.

Table 2 Mean change in retinal thickness for various OCT zones in the study eyes

\begin{tabular}{|c|c|c|c|c|c|c|c|c|c|}
\hline \multirow[b]{2}{*}{ Month } & \multicolumn{3}{|c|}{ Central subfield zone 1} & \multicolumn{3}{|c|}{ Zone of maximal oedema } & \multicolumn{3}{|c|}{$\begin{array}{c}\text { Opposite (mirror) zone of the maximal } \\
\text { thickness zone in the study eye }\end{array}$} \\
\hline & $1-3$ & $1-6$ & $3-6$ & $1-3$ & $1-6$ & $3-6$ & $1-3$ & $1-6$ & $3-6$ \\
\hline Mean & 6.3 & 5.9 & 7.7 & 9.1 & 12.0 & 7.6 & 0.26 & 0.04 & -0.25 \\
\hline SD & 28.9 & 34.2 & 47.8 & 21.9 & 23.8 & 22.7 & 17.9 & 15.0 & 15.2 \\
\hline SE & 5.37 & 6.6 & 9.2 & 4.2 & 4.6 & 4.4 & 3.5 & 2.9 & 2.9 \\
\hline$t$-test & 0.13 & 0.18 & 0.20 & 0.01 & 0.01 & 0.04 & 0.47 & 0.50 & 0.47 \\
\hline
\end{tabular}

Means and statistics of reduction of study eyes' retinal thickness, for various OCT zones, between baseline and the end of the study. $t$-test gives the probability that the observed change is not different to zero. Significant results are emboldened ( $n=34$ eyes). The $95 \%$ confidence intervals can be obtained by adding or subtracting $2.045 \times$ SE from the means.

Table 3 Each fellow eye is treated as control for its study eye (Change in study eye) - (Change in fellow eye) $(\mu \mathrm{m})$

\begin{tabular}{lcccc}
\hline Zone & Mean & SE & $95 \%$ CI & P-value \\
\hline Central & -11 & 1.92 & $-14.7 \ldots-.6 .9$ & 0.026 \\
Maximal & -13 & 2.26 & $-17.5 \ldots-7.2$. & 0.052 \\
Mirror & 2.4 & 2.41 & $-2.5 \ldots 7.3$ & 0.144 \\
\hline
\end{tabular}

Each fellow eye is treated as control for its study eye The retinal thickness in study eyes shrinks to a greater extent than in the fellow eye for the central zone and the zone of maximal swelling but only reaches significance for the central zone. The increase in thickness of the mirror zone is insignificant.

decreases in 18 . For study eyes, swelling increases in 8 and decreases in 26.

\section{Psychophysical testing and achromatic contrast sensitivity testing}

The average thresholds of illuminated and fellow eyes at baseline were not significantly different ( $t$-test: $P=0.39$ for acuity and 0.214 for contrast sensitivity) but after 6 months the difference between study and fellow eyes had increased ( $P=0.001$ for acuity and 0.054 for contrast sensitivity). Note that the average final visual acuity of $>80$ letters read corresponds to a value slightly better than 20/20.

Of the 13 patients initially having BCVA $<80$ in the study eyes, 10 improved by 5 letters or more. For fellow eyes, corresponding numbers were 9 of whom 3 improved, 6 remain unchanged, while 3 deteriorate by $>3$ letters (Fisher exact test gives $P=0.054$ ). Contrast sensitivity increased by 3 or more letters on Pelli-Robson charts in 11 trial eyes, remained unchanged in 6 , while 3 deteriorate by more than 3 letters. In only 1 of the 9 patients with an initial score of $<28$ letters was there deterioration (Fisher exact $P=0.003$ ). The results are shown in Table 4 .

Table 5 summarises the results from microperimetry. Patients found it difficult to carry out the test, and only 25 complete results were obtained 3 months, and the test was then abandoned. The sensitivity of the central area and the peripheral zones of treated eyes increased while it decreased in the untreated eyes.

\section{Discussion}

\section{Synopsis of results}

This relatively small study has provided evidence that in patients with very early DMO, significant local 
morphological and functional improvements occur in the eye exposed to light during sleep. In untreated eyes, any morphological change is a deterioration.

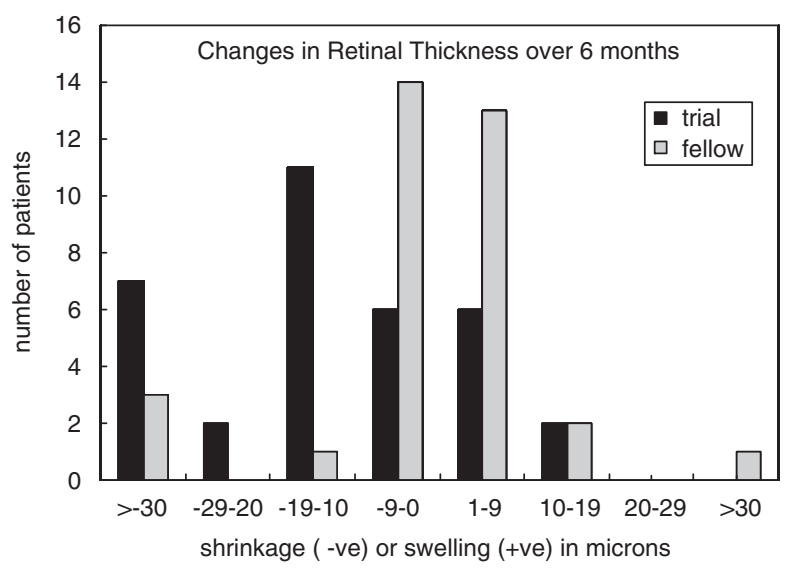

Figure 3 Magnitude of reduction in retinal thickness of the worse affected ETDRS zone of treated and fellow eyes, where swelling was maximal. This zone $(2,3,4$, or 5$)$ was determined by the initial measurement and subsequent shrinkage or swelling was determined for that zone. The zone number differed from patient to patient. The fellow eye results are distributed equally around zero, but the changes in the study eyes indicate that there was considerable more shrinkage than swelling. Note such results are not distributed in a Gaussian manner. See Discussion for a possible explanation.

\section{Possible explanations}

The mean OCT changes are however small, because we confined recruitment to the earliest stage of the condition. In such patients, local regions of oedema may disappear but the general course of the disease is a progression, and as one region of leakage reduces others may take its place. This cannot explain our results in the study eyes: the 'mirror zones' did not change. Standard statistical methods thus show that the changes associated with treatment are unlikely to be due to chance. We have not included in the analysis the results of the four patients withdrawn from the study because only the unilluminated eyes required lasering during the study period. This also underestimates the significance of the results. In psychophysical tests, the average magnitude of the improvement was small. But a high proportion of our patients had normal or nearly normal acuity at study onset, so the changes are subject to the 'ceiling effect': in those with initially reduced acuity, 10 of 13 showed improvement of $>5$ letters. Most of the improvement occurred in the first 3 months of the study, though often return to normality was observed in the latter half of the short study. By contrast, there was deterioration of these other measures of function in untreated eyes.

\section{Study limitations and failings}

We have not conducted a double-masked randomised study. This is partly due to lack of resources. The

Table 4 Changes in psychophysical tests

\begin{tabular}{|c|c|c|c|c|c|c|c|c|c|}
\hline \multirow[t]{3}{*}{ Test } & \multicolumn{4}{|c|}{ Study eyes } & \multicolumn{4}{|c|}{ Fellow eyes } & \multirow{3}{*}{$\begin{array}{l}\text { Change and } 95 \% \\
\text { CI after } 6 \text { months }\end{array}$} \\
\hline & \multicolumn{2}{|c|}{ Initial values } & \multicolumn{2}{|c|}{ Final values } & \multicolumn{2}{|c|}{ Initial values } & \multicolumn{2}{|c|}{ Final values } & \\
\hline & Mean & $S D$ & Mean & $S D$ & Mean & $S D$ & Mean & $S D$ & \\
\hline \multirow[t]{2}{*}{ Visual acuity (ETDRS letters) } & 78.04 & 7.80 & 80.18 & 5.32 & 76.52 & 8.10 & 74.59 & 8.52 & 4.21 \\
\hline & \multicolumn{2}{|c|}{ Range 85-60 } & \multicolumn{2}{|c|}{ Range 85-60 } & \multicolumn{2}{|c|}{ Range 86-67 } & \multicolumn{2}{|c|}{ Range 87-47 } & $2.64-5.78$ \\
\hline \multirow{2}{*}{$\begin{array}{l}\text { Constrast sensitivity (Pelli-Robson) } \\
\text { letters read }\end{array}$} & 31.71 & 5.39 & 33.14 & 4.57 & 30.16 & 4.71 & 30.50 & 4.95 & 2.00 \\
\hline & \multicolumn{2}{|c|}{ Range 38-20 } & \multicolumn{2}{|c|}{ Range $41-20$} & \multicolumn{2}{|c|}{ Range 36-23 } & \multicolumn{2}{|c|}{ Range 36-20 } & $1.25-2.75$ \\
\hline
\end{tabular}

Summary of results of visual acuity and contrast sensitivity testing in study and fellow eyes.

Table 5 Summary of microperimetry results in trial eyes for first 3 months of trial

Microperimetry results: mean retinal sensitivity in $d B$

\begin{tabular}{|c|c|c|c|c|c|c|}
\hline & \multicolumn{4}{|c|}{ Means $\pm S D: \mathrm{n}=25$} & & \\
\hline & \multicolumn{2}{|c|}{ Zone 1} & \multicolumn{2}{|c|}{ Mean of zones 2-9 } & \multicolumn{2}{|c|}{ Change 0-3 months } \\
\hline & Initially & 3 months & Initially & 3 months & Zone 1 & Zone 2-9 \\
\hline Study eye & $14.13 \pm 3.42$ & $14.86 \pm 3.43$ & $14.85 \pm 2.47$ & $15.67 \pm 2.44$ & -0.94 & -0.97 \\
\hline Fellow eye & $14.46 \pm 4.17$ & $12.58 \pm 5.00$ & $14.55 \pm 3.60$ & $13.33 \pm 4.75$ & 1.13 & 0.54 \\
\hline \multicolumn{3}{|c|}{$t$-test (study-fellow) } & & & $P=\mathbf{0 . 0 0 2 7}$ & $P=\mathbf{0 . 0 0 2 1}$ \\
\hline
\end{tabular}

Significant results are shown in bold. 
light masks had a high failure rate so some patients did not have continuous periods of illumination at night. We had no means of determining whether the lightemitting diodes were always positioned in front of the pupil, or if they could become displaced during the night. The magnitude of change in individual cases (Figure 3) is not distributed normally and this could be accounted for if adequate treatment was not given in some cases. However, these failings in the mask would reduce the efficiency of the treatment, and increase the significance of any improvement associated with the use of the masks. We have measured local changes in retinal thickness to demonstrate changes in the oedema, a practice which is not 'standard' but has been previously employed. ${ }^{27}$ As in two respects - number of cysts and thickness of the ETDRS Zone 1-study and fellow eyes were not equal, it is not certain whether the fellow eyes could be used as controls for the study eyes. We have therefore carried out both inter-eye comparisons, comparison between pairs of eyes in the same individuals, and longitudinal comparisons on study eyes only. All methods of analysis indicate that the observed improvements were significant.

\section{Comparison with other trials}

Most previous trials of treatment have been designed to test the efficacy of invasive methods, and therefore treatment has been given to patients with more severe retinal changes than the patients in this study. Direct comparison of our results with other trials is therefore not possible, and our results cannot be directly used to estimate the value of the treatment for patients with more advanced disease.

\section{Implications for the pathophysiology of DR}

The lids and the media attenuate light from the mask by a factor of $\approx 100 .^{28,29}$ If all the electricity used was converted to photons, the retinal illumination would be $\approx 1 \mu \mathrm{W} / \mathrm{cm}^{2}$. Such a light level cannot cause damage to retinal structures, or significant heating, or affect the function of mitochondria. Retinal ganglion cells containing melanopsin ${ }^{30}$ respond directly to light and this has been linked with visual disturbances ${ }^{31-33}$ and circadian rhythm change associated with melatonin. The retinal illumination $(480 \mathrm{~nm})$ required to cause a $50 \%$ reduction in the night-time increase of melatonin is $25 \mu \mathrm{W} / \mathrm{cm}^{2} .^{34,35}$ The trans-lid illumination caused by the masks would therefore produce minimal changes in melatonin. The only known way for such weak light to reverse retinal changes is thus via the hypothesis already advanced, ${ }^{21}$ that during dark adaptation, rod metabolic activity increases and the resulting hypoxia stimulates the production of cytokines that cause retinal damage. Thus the study may be considered a proof of principle.

\section{Limitations of the study}

We have not encountered any adverse effect, but the study was short. Any adverse effect on the retina of low intensity, continuous illumination is most unlikely, and might even improve retinal function, if it inhibited the synchronous shedding of rod tips that occurs each dawn. ${ }^{34}$ If rods 'shed' individually throughout the day, the ability of RPE cells to phagocytose and digest rod discs might improve. In rodents, which are very susceptible to light damage, increasing the average $24 \mathrm{~h}$ illumination within tolerable limits only results in a shortening of the rod outer limb, which is autoregulatory, and results in the cell absorbing a constant 14000 photons/rod/second. ${ }^{34-38}$ We calculate that the illumination of the light masks provided only 50-500 photons absorbed/rod/sec.

\section{Generalisability}

Evidently, large-scale fully randomised and controlled clinical trials are required to establish the efficacy of this method of treatment, the quantity of light required, the long-term effects, if any, the stages in DR for which such interventions improve retinal function, and how long any improvement can be maintained.

\section{Possible significance for DR}

Providing light during sleep is inexpensive and methods of obtaining it are readily available in places where there is a constant electricity supply. The use of light masks similar to those we have made has certain advantages: the intensity of light is known, and not subject to the patient covering the eyes. The cost of running the mask compares favourably with the cost of electrical room illumination. The provision of light at night, from whatever source, may not require supervision because the non-invasive treatment has no known adverse effects. Therefore, even if the method only functions to reverse the earliest retinal diabetic changes, it might be widely adopted by people with diabetes as a prophylactic measure. However, this study does not provide any evidence that light therapy would be helpful in proliferative DR or more advanced cases of nonproliferative DR, but it might delay the onset of more serious effects of DR. 
Summary

\section{What was known before}

- Dark adaptation requires significant oxygen demand. VEGF is increased in diabetic macular oedema and the main stimulus for it is hypoxia.

\section{What this study adds}

- Trans-eyelid retina illumination causes regression of diabetic macular oedema due to decrease in dark adaptation-associated oxygen consumption.

\section{Conflict of interest}

The authors declare no conflict of interest.

\section{Acknowledgements}

We would like to thank Elizabeth Pearce, our study optometrist, Richard Leung and Matthew Richardson, our study photographers, Irene Kimm, our study coordinator, and the patients who participated in this study. We gratefully acknowledge the contribution of Diabetic Wellness to the manufacture of masks. The study itself was carried out without funding.

\section{References}

1 Mitchell P, Bandello F, Schmidt-Erfurth U, Lang GE, Massin $\mathrm{P}$, Schlingemann RO, et al., RESTORE study group. The RESTORE study: ranibizumab monotherapy or combined with laser vs laser monotherapy for diabetic macular edema. Ophthalmology 2011; 118(4): 615-625.

2 Salam A, DaCosta J, Sivaprasad S. Anti-vascular endothelial growth factor agents for diabetic maculopathy. $\mathrm{Br} \mathrm{J}$ Ophthalmol 2010; 94: 821-826.

3 Elman MJ, Aiello LP, Beck RW, Bressler NM, Bressler SB, Edwards AR, Diabetic Retinopathy Clinical Research Network et al. Randomized trial evaluating ranibizumab plus prompt or deferred laser or triamcinolone plus prompt laser for diabetic macular oedema. Ophthalmology 2010; 117: 1064-1077.

4 Michaelides M, Kaines A, Hamilton RD, Fraser-Bell S, Rajendram $\mathrm{R}$, Quhill $\mathrm{F}$ et al. A prospective randomized trial of intravitreal bevacizumab or laser therapy in the management of diabetic macular oedema (BOLT study) 12month data: report 2. Ophthalmology 2010; 117: 1078-1086.

5 Azza El-Remessy M, Ali Behzadian A, Abou-Mohamed G, Franklin T, Caldwell RW, Caldwell RB. Experimental diabetes causes breakdown of the blood-retina barrier by a mechanism involving tyrosine nitration and increases in expression of vascular endothelial growth factor and urokinase plasminogen activator receptor. Am J Pathol 2003; 162: 1995-2004.

6 Braun RD, Linsenmeier RA, Goldstick TK. Oxygen consumption in the inner and outer retina of the cat. Invest Ophthalmol Vis Sci 1995; 36: 542-554.

7 Linsenmeier RA, Braun RD, McRipley MA, Padnick LB, Ahmed J, Hatchell DL et al. Retinal hypoxia in long-term diabetic cats. Invest Ophthalmol Vis Sci 1998; 39: 1647-1657.
8 Arden GB, Wolf JE, Collier J, Wolff C, Rosenberg M. Dark adaptation is impaired in diabetic before photopic loss can be seen. Can hypoxia contribute to diabetic retinopathy?. In: Hollyfield JG (ed). Retinal Degenerative Diseases and Experimental Therapy. Plenum Press: New York, 1999, pp 305-325.

9 Dean FM, Arden GB, Dornhorst A. Partial reversal of protan and tritan colour defects with inhaled oxygen in insulin dependent diabetic subjects. Br J Ophthalmol 1997; 81: 27-30.

10 Harris A, Arend O, Danis RP, Evans S, Wolf S, Martin BJ. Hyperoxia improves contrast sensitivity in early diabetic retinopathy. Br J Ophthalmol 1996; 80: 209-213.

11 Drasdo N, Chiti Z, Owens DR, North RV. Effect of darkness on inner retinal hypoxia in diabetes. Lancet 2002; 359(9325): 2251-2253.

12 Kern TS, Engerman RL. Capillary lesions develop in retina rather than cerebral cortex in diabetes and experimental galactosemia. Arch Ophthalmol 1996; 114: 306-310.

13 de Gooyer TE, Stevenson KA, Humphries P, Simpson DA, Gardiner TA, Stitt AW. Retinopathy is reduced during experimental diabetes in a mouse model of outer retinal degeneration. Invest Ophthalmol Vis Sci 2006; 47: 5561-5568.

14 Arden GB, Wolf JE, Collier J, Wolff C, Rosenberg M. Dark adaptation is impaired in diabetics before photopic visual losses can be seen. Hollyfield et al. (eds). Retinal Degenerative Diseases and Experimental Therapy. Kluver Academic Plenum: New York, 1999, pp 305-316 Ch. 29.

15 Arden GB. The absence of diabetic retinopathy in patients with retinitis pigmentosa: implications for pathophysiology and possible treatment. Brit J Ophthalmol 2001; 85: 366-370.

16 Nguyen QD, Shah SM, Van Anden E, Sung JU, Vitale S, Campochiaro PA. Supplemental oxygen improves diabetic macular oedema: a pilot study. Invest Ophthalmol Vis Sci 2004; 45: 617-624.

17 Shiba T, Sato Y, Takahashi M. Relationship between diabetic retinopathy and sleep-disordered breathing. Am J Ophthalmol 2009; 147: 1017-1021.

18 West SD, Groves DC, Lipinski HJ, Nicoll DJ, Mason RH, Scanlon $\mathrm{PH}$ et al. The prevalence of retinopathy in men with Type 2 diabetes and obstructive sleep apnoea. Diabet Med 2010; 27: 423-430.

19 Busik JV, Mohr S, Grant MB. Hyperglycaemia-induced reactive oxygen species toxicity to endothelial cells is dependent on paracrine mediators. Diabetes 2008; 57 : 1952-1965.

20 Arden GB, Wolf JE, Tsang Y. Does dark adaptation exacerbate diabetic retinopathy? Evidence and a linking hypothesis. Vision Res 1998; 38: 1723-1729.

21 Arden GB, Sidman RL, Arap W, Schlingemann RO. Spare the rod and spoil the eye. Br J Ophthalmol 2005; 89: 764-769.

22 Arden GB. Comments on 'A new view of diabetic Retinopathy' by AJ Barber. Prog Neuropsychopharmacol Biol Psychiatry 2004; 28: 747-748.

23 Hagins WA, Ross PD, Tate RL, Yoshikami S. Transduction heats in retinal rods: tests of the role of cGMP by pyroelectric calorimetry. Proc Natl Acad Sci USA 1998; 86: 1224-1228.

24 Hamer RD, Nicholas SC, Tranchina D, Lamb TD, Jarvinen JL. Toward a unified model of vertebrate rod phototransduction. Vis Neurosci 2005; 22: 417-436.

25 Birol G, Wang S, Budzynski E, Wangsa-Wirawan ND, Linsenmeier RA. Oxygen distribution and consumption in the macaque retina. Am J Physiol Heart Circ Physiol 2007; 293: H1696-H1704. 
26 Arden GB, Gündüz MK, Kurtenbach A, Völker M, Zrenner E, Gündüz SB et al. Preliminary trial to determine whether prevention of dark adaptation affects the course of early diabetic retinopathy. Eye 2010; 24: 1149-1155.

27 Reznicek L, Kernt M, Haritoglou C, Kampik A, Ulbig M, Neubauer AS. In vivo characterization of ischemic retina in diabetic retinopathy. Clin Ophthalmol 2011; 5: 31-35.

28 Sliney DH, Wolbarsht ML. Safety with Lasers and Other Optical Sources. Plenum Press: New York, 1980.

29 Robinson J, Bayliss S, Fielder AR. Transmission of light across the adult and neonatal eyelid in vivo. Vision Res 1991; 31: 1837-1840.

30 Berson DM, Dunn FA, Takao M. Phototransduction by retinal ganglion cells that set the circadian clock. Science 2002; 295: 1070-1073.

31 Stevens RG. Electric light causes cancer? Surely you're joking, Mr. Stevens. Mutat Res 2009; 682: 1-6.

32 Brainard GC, Hanifin JP, Greeson JM, Byrne B, Glickman G, Gerner $\mathrm{E}$ et al. Action spectrum for melatonin regulation in humans: evidence for a novel circadian photoreceptor. J Neurosci 2001; 21: 6405-6412.
33 Thapan, Arendt J, Skene DJ. An action spectrum for melatonin suppression: evidence for a novel non-rod, non-cone photoreceptor system in humans. J Physiol 2001; 535: 261-267.

34 Young RW. The renewal of rod and cone outer segments in the rhesus monkey. J Cell Biol 1971; 49: 313-318.

35 Schremser JL, Williams TP. Rod outer segment (ROS) renewal as a mechanism for adaptation to a new intensity environment. I. Rhodopsin levels and ROS length. Exp Eye Res 1995; 61: 17-23.

36 Williams TP, Henrich S, Reiser M. Effect of eye closures and openings on photostasis in albino rats. Invest Ophthalmol Vis Sci 1998; 39: 603-609.

37 Williams TP, Webbers JP, Giordano L, Henderson RP Distribution of photon absorption rates across the rat retina. J Physiol 1998; 508: 515-522.

38 Williams TP, Squitieri A, Henderson RP, Webbers JP Reciprocity between light intensity and rhodopsin concentration across the rat retina. J Physiol 1999; 516: 869-874. 